\title{
The value of serum IgG titres against Pseudomonas aeruginosa in the management of early pseudomonal infection in cystic fibrosis
}

\begin{abstract}
We report the results of a clinical trial. Patients enrolled had serum IgG titres against Pseudomonas aeruginosa above the control range. Assignment to the observation or treatment group was by minimisation. Significant signs or symptoms in any patient prompted antipseudomonal treatment. In addition, the treatment group received antipseudomonal treatment at intervals of four months until the serum IgG titre returned to the control range. $P$ aeruginosa was isolated intermittently from patients in the main trial. Nineteen patients were enrolled (12 observation, seven treatment). After one year in the trial changes in parameters studied, including forced expiratory volume in one second, IgG titre, serum IgG concentrations, and frequency of $P$ aeruginosa isolation had improved in the treated group and worsened in the observation group.
\end{abstract}

\section{(Arch Dis Child 1992;67:1086-8)}

Pulmonary infection with Pseudomonas aeruginosa is an important cause of morbidity and mortality in patients with cystic fibrosis. ${ }^{1}$ Once the organism has become established in the lungs it is never completely eradicated, even after aggressive antimicrobial treatment, hence the early stages of infection of the airways and lungs are important.

In the past, there were two major problems associated with assessing the presence and severity of the early stages of infection: first, the significance of a few intermittent isolations of $P$ aeruginosa was unclear. Secondly, there were no consistent changes in any clinical or immunological parameter until infection became chronic and ineradicable, so it was not always clear whether treatment was necessary and, if given, whether it had been beneficial.

Measurement by enzyme linked immunoadsorbent (ELISA) of serum IgG antibodies specific for $P$ aeruginosa seemed to overcome these problems. In chronically infected patients the IgG titre correlated significantly with clinical measures of the severity of infection and the response to treatment. ${ }^{2}$ Furthermore, an increase in titre, to above the control range, preceded isolation of the organisms in the majority of patients. ${ }^{34}$ It is possible that antibiotic treatment given to patients in the early stages of pseudomonal infection, indicated only by a rise in antibody titres to above control values, may be effective in eradicating $P$ aeruginosa, and preventing or delaying the onset of pseudomonal infection.
This study was designed to determine the effect of antipseudomonal treatment on patients with raised serum IgG titres and intermittent isolations of the organism.

\section{Patients and methods}

PATIENTS

All patients attended the paediatric and adult cystic fibrosis clinics at our hospital. The criteria for entry were patients who had $P$ aeruginosa isolated from respiratory cultures and who had a modest increase in serum IgG titre (270-2000). Patients with chronic symptomatic chest infection associated with high titres $(>2000)$ and patients on corticosteroid treatment or nebulised antipseudomonal antibiotic treatment were excluded from entry.

Patients were assigned to a treatment or observation arm in each trial. Allocation was done by minimisation ${ }^{5}$ after stratification for age (0-10 years, 11-20 years, $>20$ years), sex (male, female), Shwachman score $(<70,70-85$, 86-100) ${ }^{6}$ and Chrispin-Norman score $(0-10$, $11-20,>20){ }^{7}$

\section{TRIAL PROTOCOL}

In the treatment group patients received a course of intravenous antibiotics for two weeks on entry to the trial. ${ }^{8}$ Normally, a combination of tobramycin and a ureido-penicillin was used but in cases of resistance to these antibiotics an alternative was used, for example ceftazidime. Courses of intravenous antibiotics were repeated every four months until the IgG titre returned to the control range. If the IgG titre returned to the control range after treatment, the titre was checked every two months. If the titre subsequently rose to values above the control range, a two week course of intravenous antibiotics was given immediately and repeated at intervals of four months until the titre returned to the control range.

In the observation group patients received their usual treatment for cystic fibrosis which includes long term antistaphylococcal treatment, regular physiotherapy, high energy diet, and supplements of pancreatic enzymes and vitamins.

If significant symptoms developed in any patient in the study, which were considered to be associated with $P$ aeruginosa infection, appropriate intravenous treatment was given according to our standard regimen. ${ }^{8}$ If minor symptoms developed in any patient in the study, for example an increase in cough, or sputum production, considered to be due to other pathogens such as Staphylococcus aureus or 
Haemophilus influenzae then appropriate oral treatment was given.

On entry to the trial and at intervals of six months patients were assessed clinically in detail. Investigations included measurement of growth, respiratory function (peak expiratory flow rate, forced expiratory volume in one second $\left(F E V_{1}\right)$, forced vital capacity), haemoglobin, white cell count (total and differential), erythrocyte sedimentation rate, plasma viscosity, $C$ reactive protein, and serum IgG, $\operatorname{IgA}, \operatorname{IgM}$, and IgE concentrations. These were also measured at the beginning and end of every course of treatment. The serum IgG antipseudomonal titre was measured every two months and at the beginning and end of every course of treatment. Cultures of sputum and throat swabs were performed every month or more frequently if an infection was suspected or present.

\section{STATISTICAL ANALYSES}

The Student's $t$ test and the Mann-Whitney U test were used. Significance levels were for two tailed tests. 9

\section{Results}

Nineteen patients were enrolled into this trial. Clinical and laboratory parameters on entry for the observation and treated groups are shown in table 1 .

Patients were developing early signs of chronic respiratory infection. Many had recently acquired a new persistent cough which had not settled despite courses of oral antibiotics. Chest radiographs showed early changes characteristic of cystic fibrosis with hyperinflation and some bronchial wall thickening. They had some impairment in respiratory function tests.

Table 1 Clinical data for patients on trial entry

\begin{tabular}{lcc}
\hline & $\begin{array}{l}\text { Observation } \\
\text { group } \\
(n=12)\end{array}$ & $\begin{array}{l}\text { Treated } \\
\text { group } \\
(n=7)\end{array}$ \\
\hline M/F & $5 / 7$ & $2 / 5$ \\
Age in years (range) & $14(6-29)$ & $13(7-19)$ \\
Mean (SD) Shwachman score & $85(3 \cdot 6)$ & $75(4 \cdot 0)$ \\
Range & $75-90$ & $55-95$ \\
Mean (SD) Chrispin-Norman score & $6 \cdot 0(1 \cdot 8)$ & $10 \cdot 1(1 \cdot 8)$ \\
Range & $3-11$ & $5-18$ \\
Mean (SD) weight for height & & \\
(\% predicted) & $87 \cdot 0(1 \cdot 8)$ & $90 \cdot 0(0 \cdot 8)$ \\
Range & $76-97$ & $75-94$ \\
\hline
\end{tabular}

Results presented in table 2 show that on entry to the trial the treated group had worse $\mathrm{FEV}_{1}$, serum IgG antipseudomonal titre, and serum IgG concentration than the observation group. After one year in the trial these parameters had improved in the treated group and deteriorated in the observation group. The annual rate of increase of serum IgG antipseudomonal titre was 520 in the observation group while it decreased by 125 in the treated group. $F_{1} V_{1}$ predicted remained constant in the observation group over one year but improved by $11 \%$ in the treated group. Serum IgG concentration increased in the observation group but remained unchanged in the treated group.

The proportion of respiratory cultures that were positive for $P$ aeruginos $a$ in the observation group increased from $62 \%$ in the three months immediately preceding entry to $93 \%$ in the period 12 months after entry. The proportion of pseudomonal isolates which were mucoid increased from $14 \%$ to $39 \%$ in the same period. In contrast, the proportion of cultures which were positive for $P$ aeruginos $a$ and the proportion of pseudomonal isolates which were mucoid remained essentially unchanged in the treated group. After one year the proportion of $P$ aeruginosa positive cultures and the proportion of mucoid isolates were significantly lower in the treated than the observation group $(p<0.001$ and $\mathrm{p}<0 \cdot 10$ respectively).

\section{Discussion}

This trial was designed to test our preliminary findings that an increased antipseudomonal antibody titre was an early sign of pseudomonal infection of the respiratory tract which, in many patients with cystic fibrosis, precedes isolation of the organism from the respiratory tract. ${ }^{2-4}$ It was also designed to determine whether very early antipseudomonal treatment (that is before the organism has been isolated and during the first few months of its isolation) would delay the clinical deterioration associated with pseudomonal infection. We therefore excluded patients who had an IgG titre of $>2000$ as earlier studies suggested that by this stage infection was chronic and irreversible. ${ }^{2-4}$

Treated patients have progressed better than the observation group in every parameter

Table 2 Clinical and laboratory parameters for patients on trial entry and after one year

\begin{tabular}{|c|c|c|c|c|c|c|}
\hline & \multicolumn{3}{|l|}{ On entry } & \multicolumn{3}{|c|}{ After one year } \\
\hline & $\begin{array}{l}\text { Observation } \\
\text { group } \\
(n=12)\end{array}$ & $\begin{array}{l}\text { Treated } \\
\text { group } \\
(n=7)\end{array}$ & $p$ Value & $\begin{array}{l}\text { Observation } \\
\text { group } \\
(n=12)\end{array}$ & $\begin{array}{l}\text { Treated } \\
\text { group } \\
(n=7)\end{array}$ & $p$ Value \\
\hline $\begin{array}{l}\text { Serum IgG titre } \\
\text { Range } \\
\text { FEV }(\% \text { predicted) } \\
\text { Range } \\
\text { WCC }\left(\times 10^{\%} / 1\right) \\
\text { Range } \\
\% \text { Neutrophils } \\
\text { Range } \\
\text { Serum IgG (g/l) } \\
\text { Range } \\
\% \text { Cultures positive: }\end{array}$ & $\begin{array}{l}685 \\
260-1400 \\
75 \\
64-94 \\
7 \cdot 9 \\
5 \cdot 3-14 \cdot 7 \\
51 \\
41-70 \\
9 \cdot 5 \\
6 \cdot 0-13 \cdot 4\end{array}$ & $\begin{array}{l}805 \\
330-1363 \\
67 \\
47-102 \\
8 \cdot 8 \\
5 \cdot 0-13 \cdot 8 \\
59 \\
44-83 \\
13 \cdot 97 \\
8 \cdot 0-20 \cdot 5\end{array}$ & $\begin{array}{l}\text { NS } \\
\text { NS } \\
\text { NS } \\
\text { NS } \\
<0 \cdot 10\end{array}$ & $\begin{array}{l}1205 \\
390-5200 \\
75 \\
41-92 \\
7 \cdot 5 \\
6 \cdot 0-9 \cdot 9 \\
54 \\
44-71 \\
11 \cdot 3 \\
6 \cdot 9-14 \cdot 0\end{array}$ & $\begin{array}{l}680 \\
260-1915 \\
78 \\
55-110 \\
7 \cdot 7 \\
5 \cdot 0-11 \cdot 6 \\
61 \\
49-75 \\
13 \cdot 3 \\
6 \cdot 0-20 \cdot 6\end{array}$ & $\begin{array}{l}<0.05 \\
\text { NS } \\
\text { NS } \\
\text { NS } \\
\text { NS }\end{array}$ \\
\hline $\begin{array}{l}\text { Non-mucoid } P \text { aeruginosa } \\
\text { Mucoid } P \text { aeruginosa } \\
\text { No of courses antipseudomonal } \\
\text { treatment/patient }\end{array}$ & $\begin{array}{l}62 \\
14\end{array}$ & $\begin{array}{r}49 \\
9\end{array}$ & $\begin{array}{l}\text { NS } \\
\text { NS }\end{array}$ & $\begin{array}{l}93 \\
39 \\
1.09\end{array}$ & $\begin{array}{l}51 \\
7 \\
2 \cdot 8\end{array}$ & $\begin{array}{l}<0 \cdot 001 \\
<0 \cdot 10\end{array}$ \\
\hline
\end{tabular}


studied. There was a significant difference during the study period in changes in the treated and observation groups in serum IgG titre, $\mathrm{FEV}_{1}$, serum IgG concentrations, and in the proportion of pseudomonas positive respiratory cultures.

We conducted a similar trial with patients from whom $P$ aeruginosa had not yet been isolated but who had specific antibody titres greater than the control range. These patients were normally asymptomatic and respiratory cultures normally grew no pathogens. The Chrispin-Norman $x$ ray scores were 80-95 (mean 88) and 90-95 (mean 93) in the observation and treated groups respectively. $\mathrm{FEV}_{1}$ (\% predicted) was 65-116 (mean 86) and 79-88 (mean 83 ) in the observation and treated groups respectively.

Patients in this second trial were initially in a very good clinical state and changes in clinical parameters were small during the study period, so differences between the observation and treated groups were not statistically significant. There was, however, a similar pattern to that seen in the larger trial: a deterioration in the observation group and improvement or no change in the treated group. After six months in the trial, serum IgG antipseudomonal titres had increased in the observation group to $360-700$ (mean 374) from 300-540 (mean 327) on entry but had decreased slightly in the treated group to 187-320 (mean 260) from 273-350 (mean 296) on entry.

The need for regular venepuncture to check antibody titres caused distress among some of the patients. Future monitoring of values could be done by finger prick sampling which has been shown to be adequate for detecting serum IgG to antibodies to $P$ aeruginosa and may be more acceptable to some parents and patients. ${ }^{10}$ Admissions for courses of intravenous antibiotic treatment, particularly in relatively well patients, inevitably caused some disruption to family life. The oral antipseudomonal antibiotic ciprofloxacin became available during the study and was a major factor leading to the premature discontinuation of these trials. Ciprofloxacin has been shown to be as effective as a course of intra- venous antibiotics in one study, ${ }^{11}$ while other work shows ciprofloxacin to be comparable in mildly affected patients but less effective in severely affected patients. ${ }^{12}$

This trial has confirmed the value of IgG antipseudomonal antibody measurement in monitoring the development and treatment of patients with cystic fibrosis with early respiratory infection. Early and repeated antipseudomonal antibiotic treatment appears to be beneficial for these patients. We intend to continue monitoring antibody titres in our patients and treating early infection with courses of oral antipseudomonal antibiotics.

We gratefully acknowledge the Cystic Fibrosis Trust for their financial support of Dr M M Brett and Dr E J Simmonds which made this work possible. We thank Dr S P Conway and Dr R L Page for allowing us to study their patients.

1 Mearns MB, Hunt GH, Rushworth R. Bacterial flora of respiratory tract in patients with cystic fibrosis, 1950-1971. respiratory tract in patients with
Arch Dis Child 1972;47:902-7.

2 Brett MM, Ghoneim ATM, Littlewood JM. Serum antibodies to Pseudomonas aeruginosa in cystic fibrosis. Arch Dis Child 1986;61:1114-20.

3 Brett MM, Ghoneim ATM, Littlewood JM. Serum IgG antibodies in patients with cystic fibrosis with early Pseudomonas aeruginosa infection. Arch Dis Child 1987;62 357-61.

4 Brett MM, Ghoneim ATM, Littlewood JM. Prediction and diagnosis of early Pseudomonas aeruginosa infection in cystic fibrosis in a follow up study. 7 Clin Microbiol 1988 26:1565-70.

5 Pocock SJ, Simon R. Sequential treatment assignment with balancing for prognostic factors in the controlled clinical balancing for prognostic factor
trial. Biometric 1975;31:103-15.

6 Shwachman H, Kulczycki LK. Long term study of one hundred and five patients with cystic fibrosis. Am $7 \mathrm{Dis}$ hundred and five pat

7 Chrispin AR, Norman AP. The systemic evaluation of the chest radiograph in cystic fibrosis. Pediatr Radiol 1974;2: chest rad $101-6$.

8 Conway SP, Miller MG, Ramsden G, Littlewood JM. Intensive treatment of pseudomonas chest infection in cystic fibrosis: a comparison of tobramycin and ticarcillin and netilmicin and ticaracillin. Acta Paediatr Scand 1985;74. 107-13.

9 Lentner C, ed. Geigy scientific tables. 8th Ed. Basle: CibaGeigy, 1982:30-33, 163, 208, 210,230.

10 Thanasekaraan V, Wiseman MS, Rayner RJ, Hiller EJ, Shale DJ. Pseudomonas aeruginosa antibodies in blood spots from patients with cystic fibrosis. Arch Dis Child 1989;64:1599-603.

11 Hodson ME, Roberts CM, Butland RJ, Smith MJ, Batten JC. Oral ciprofloxacin compared conventional intravenous treatment for Pseudomonas aeruginosa infections in adults treatment for Pseudomonas aeruginosa infect
with cystic fibrosis. Lancet 1987;1:235-7.

12 Jensen T, Pedersen SS, Hoiby N, Koch C. Efficacy of oral fluoroquinolones versus conventional antipseudomonal chemotherapy in treatment of cystic fibrosis. European chemotherapy in treatment of cystic fibrosis.
fournal of Clinical Microbiology 1987;6:618-22. 